\title{
A decrease in psycho-emotional health in middleaged Russian women associated with their lifestyle: factors and indicators
}

\author{
Maria V. Saporovskaia ${ }^{1}$, Tatiana L. Kryukova2,*, Maria E. Voronina ${ }^{3}$, Elena V. Tikhomirova ${ }^{4}$, \\ Anna G. Samokhvalova ${ }^{5}$, Svetlana A. Khazova ${ }^{6}$ \\ ${ }^{1}$ Department of General and Social Psychology; Kostroma State University, Kostroma, Russia, 156005; \\ saporov35@mail.ru \\ ${ }^{2}$ Department of General and Social Psychology; Kostroma State University, Kostroma, Russia, 156005; \\ tat.krukova44@gmail.com \\ ${ }^{3}$ Municipal gymnasium N 1, Galich , Kostroma Region, Russia, 157200; mariaantonvoron@mail.ru \\ ${ }^{4}$ Department of General and Social Psychology; Kostroma State University, Kostroma, Russia, 156005; \\ tichomirowa82@mail.com \\ ${ }^{5}$ Department of Education and Acmeology; Kostroma State University, Kostroma, Russia, 156005; \\ a samohvalova@ksu.edu.ru \\ ${ }^{6}$ Department of Special Education and Psychology; Kostroma State University, Kostroma, Russia, 156005; \\ hazova_svetlana@mail.ru \\ Tatiana L. Kryukova ${ }^{2, *}$ Correspondence: tat.krukova44@gmail.com; Tel.: +74942 31-84-16; +7903-896-01-88
}

\begin{abstract}
Background: The present study is aimed to determine the predicting role of objective (lifestyle) and subjective factors of middle-aged women's psycho-emotional health such as their attitude towards parents, attachment and separation types. Women who are overloaded with professional and family roles have high stress level, their indicators of psychological well-being and emotional level decrease when they have to give everyday care to their elderly parents. (2) Methods: Sample consists of 146 women aged 38 to $56(\bar{X}=41.1, \quad$ ó $=3.5)$, married (70.5\%) and divorced (29.5\%), having children of $14-28$ years old; giving everyday care to elderly parents for more than 1.5 yrs. Some live separately $(62.3 \%)$, or have to cohabitate with parents $(37.7 \%)$. All women evaluate their life situation as difficult and manifest signs of high psycho-emotional stress. We used methods adapted for the Russian-speaking sample: getting socio-demographic information, an interview; Attachment style and Interpersonal Guilt Questionnaires (study 1); Psychological Separation Inventory, Purpose-in-Life Test, projective methods of incomplete sentences and metaphors' analysis (study 2), mathematical statistics. (3) Results: A number of factors and indicators of women's psycho-emotional health decrease in the situation of role overload have been identified. Among the factors there are four main types of women's attitudes towards parents: strong (anxious), distancing, ambivalent, normative closeness, predicting low indicators of psycho-emotional health: dependence on the others' opinions and feedbacks in making decisions, a lack of meaningfulness of life; reduced sense of control over life are showing the decrease. Anxiety about future and neurotic symptoms (increased demands on oneself, irritability, reduced emotional background) distinguish these respondents. (4) Conclusions: The study confirms that middle-aged Russian women's psycho-emotional health depends on contextual factors (difficult role-overloaded lifestyle) and factors integrating women's attitudes towards parents, attachment and separation types. Among the most important risk factors there are a difficult life situation, conflict separation type and gilt.
\end{abstract}

Keywords: women; health; psycho-emotional well-being; factors; attitudes towards parents; attachment 


\section{Introduction}

The change in the usual routine and in economic relations, stratification in society and gender inequality as well as political, economic, sociocultural and ecological threats result in psychological overloads, changes in the lifestyle and in mentality of contemporary females, who remain a vulnerable social group even in the $21^{\text {st }}$ century. Antonio Guterres, the UN Secretary-General, emphasized that the coronavirus-related crisis made the life situation for many women worse in a variety of countries, and asked world governments to make protection from gender-based violence the priority in their plans to cope with the consequences of the COVID-19 pandemic [1].

Female vulnerability in Russia is obvious. Women's routine is the history of coping with difficulties on their own, survival skills, coping with the situation and, at the same time, of self-development. A typical Russian woman is oriented at a full-time professional job and a promotion together with her family duties and child rearing [2]. At the same time, financially women are in the inferior position in comparison with men. The average income of females in January 2020 made only $67.9 \%$ of the average male income. The industrial segregation will maintain the inequality in the future [2]. However, women in Russia live longer than men by approximately 10 years (77.82 years in 2018) [3].

Meanwhile, women nowadays, including Russia, have a high level of education and professional and career interests. Moreover, child rearing and childcare are also female duties, which make it hard for women to combine family and professional duties [4, 5]. Describing a professionally successful woman, researchers use such terms as double load, role conflict, double career etc. [6, 7]. Research in gender psychology shows that gender conflicts, related to the need to combine professional and family roles, lead to the increase in stress levels in women, whereas the indicators of psychological well-being decrease together with the emotional tone [5,8]. It leads to the low satisfaction with marriage and to difficulties in self-actualization. In turn, it leads to the deterioration of psychological health that, according to the WHO, is determined by mental and psychological well-being [9]. Evidence shows that the psychological and physical condition of females in the situation of a chronic family stress leads to subjectively felt helplessness and pointlessness of effort $[10,11]$. The accumulating exhaustion stemming from low results and hard efforts and the inability to satisfy own needs can gradually result in the female's depletion of adaptation resources and may lead to the deteriorated psycho-emotional health and well-being [12, 13].

However, not only the need to combine professional, spousal and parental roles can lead to lack of well-being. The period between 35 and 55 years of age, i.e. the middle age of a woman, is the time of systemic changes in family relations (mainly, the attitude to growing children and ageing parents) [14]. These changes often cause stress and take a high toll on the woman's resources $[15,16]$. The functional roles related to care for elderly parents are still highly feminized in Russia. As a rule, this challenge is met by middle-age women. This life situation is usually described as the vertical change -adult children become "parents" towards their own elderly parents. Psychologically, the situation is hard for both ex-children and ex-parents. As the system of care for the elderly is poorly developed in Russia and the low level of income prevents families from hiring nurses, women are often left to face the problem on their own.

Recent years have seen a number of research papers on psychological problems of those who for their elderly relatives $[17,18]$. There is evidence that women who care for their aged parents with health problems risk their own health: caregivers to Alzheimer patients lose from four to eight years of life, women who for cancer patients have a weakened immune system [19].

Therefore, middle-aged women face the need to solve simultaneously three major life problems (triple load): professional career; care for their own family and the change in relations with growing children; daily care for elderly relatives. The unity and complexity of these tasks are the reflection of the specific female lifestyle that inevitably influences their psychoemotional health and well-being $[10,20,21]$. However, we realise that the objectively difficult life situation can be aggravated with a number of subjective psychological factors, closely related to the specifics of family relations. 
Research questions: How does the objectively difficult life situation of middle-aged women, related to their role overload of lifestyle, makes their psychological and emotional health worse? What is the role of such subjective factors as women's attitude to parents, their attachment style and the style of separation from parents in the process? Is there the feeling of guilt? What are the negative influences of the objective and subjective factors?

\section{Materials and Methods}

\subsection{Research design}

The research was made in small towns of Kostroma Region that takes the $62^{\text {nd }}$ place out of 82 in the Russian rating of Regions as far as the life quality is concerned. The rating is based on such criteria as income level of the population, employment rates and labour market, housing conditions, security, demographics, ecological and climatic conditions, health and educational levels of the population, social facilities, level of economic development, level of small businesses development, reclamation of lands, and development of transport infrastructure).

The research sample includes 146 middle-aged women of 38-56 years old, $(\bar{X}=41.1, \mathrm{o}=3.5)$. The selection criteria included the marital status $(70.5 \%$ - married; $29.5 \%$ - divorced); children (from 14 to 28 years); the need to care for elderly parents. All the respondents have a vocational training or a degree and work in educational, commercial and medical organisations. Their income does not exceed the average figures for the region. All the respondents have been looking after one or two elderly parents on a daily basis for 1.5 years and longer. Those respondents who live separately from their parents $(62.3 \%)$ state that they live "in two houses"; $37.7 \%$ of the respondents live with their parents. The interview showed that $100 \%$ of the respondents see their life situation as difficult and experience signs of high psychological and emotional tension.

2.2. Data Collection and Measurement

The empirical data were collected from December 2017 to June 2020. The study included two stages: Study 1 was carried out from December 2017 to June 2018 with the sample of 61 women; Study 2 was conducted from August 2019 to June 2020 with 85 women.

At the first stage, both studies involved the questionnaire to collect social and demographic data (age, gender, level of education; marital status, the age of children; professional status, experience and length of care for elderly parents). Then in a face-to-face interview, each respondent was asked to describe their real life situation and subjectively evaluate everyday stress overload (high, medium, low level of stress).

The content analysis of these replies enabled the authors to identify a number of empirical references (indicators) of deteriorating psychoemotional health and well-being of women in a situation of role overload, namely, low indicators of psychological well-being, dependence on the opinion of others, and on the evaluation of others while taking important decisions, the lack of meaningfulness in life, the lack of particular aims in life, lower control over the situation around. (Study 1). The replies are characterized by the respondents' anxiety about their future and neurotic symptoms, such as high requirements set to oneself, easy excitement, irritation, low emotional tone (Study 2).

The analysis of the contemporary understanding of the problem enabled the authors to consider additional factors of deteriorating psycho-emotional health, namely the attitude to parents and the type of attachment, including irrational guilt (Study 1) and the style of separation from parents (Study 2).

The research was conducted with the following tools:

1. The questionnaire to collect social and demographic information;

2. The semi-structured interview on the topic "The image of parents and my life situation".

Study 1

3. The scales of psychological well-being, Ryff (1995) [22];

4. Semantic differential, SD, Osgood (1952/1964), modified for the study of family - conditioned states [23];

5. Attachment Style Questionnaire (ASQ), Feeney, Noller, 1994 [24]; 
6. The Interpersonal Guilt Questionnaire-67 (IGQ-67), O'Connor et al., 1987 [25];

Study 2

7. Psychological Separation Inventory (PSI), Hoffman, 1984 [26]; Dzukaeva, 2014 [27];

8. Purpose-in-Life Test (PIL), Crumbaugh, Maholic, 1969/1981[28]; Leontiev, 2013 [31];

9. The projective method of incomplete sentences, based on the principles of projective research and content analysis (Holaday, Smith, \& Sherry, 2000; McAdams \& Zeldow, 1993) [29,30];

10. The projective method of metaphors' analysis "My lifeline", Solomin, 2002 [32].

All the methods were adapted for the Russian-speaking sample.

2.3. Statistical Analysis

The collected data were processed with the software pack SPSS Statistics 22.0.

The preliminary stage involved the procedure of assessing the normality of criteria distribution through calculations in descriptive statistics by using Kolmogorov-Smirnov consent criteria (Kolmogorov-Smirnov Test). As a result, it was found that the data did not meet normality criteria and could not be processed. Therefore, it was decided to use non-parametric statistics to conduct the further analysis. The differences between the groups were assessed with the Mann-Whitney U-test. The H-criterion (Kruskal-Wallis test) was used to compare the indicators of psychological well-being in women with a different type of attachment to parents. To assess the correlation between the indicators, the ranking correlation index was used (Spearman rank R) with the Bonferroni correction for multiple hypotheses check. The one-factor dispersion analysis was applied to study the influence of separation type on the psycho-emotional health of women.

2.4. Ethical considerations

Pursuant to Federal Act On personal data No. 152 of July 27th, 2006, the respondents were informed of the research aim and gave permission to use the obtained data. The research was conducted under the supervision of the regional department of the Russian Psychological Society.

\section{Results}

\subsection{Study 1}

The major task at the first stage was to describe types of attitudes middle-aged women have towards their parents, to define the place and role of guilt towards parents in the structure of relations between children and parents. The content analysis of the materials obtained via the interview "The image of parents and my life situation" and the subsequent data analysis enabled to identify four types of attitude a middle-aged woman can have towards her parents.

Type 1. Strong (anxious) attachment (the first factor accounting for $27 \%$ of the dispersion). This type is characterized with emotional dependence of women from their parents (0.72), need in their approval (0.62), immersion in the relationship (0.55), and attachment (0.53). The relationship with parents is satisfactory, but a woman can have a set of irrational forms of guilt: survivor's guilt (0.89), separation guilt (0.78), self-hatred guilt (0.63), and responsibility guilt (0.67).

Type 2. Distancing attitude (the second factor accounting $22 \%$ of the dispersion). This type is characterized with the general dissatisfaction with the relationship (0.95), anxiety (0.92), nervous and mental tension (0.76) and the low level of closeness (0.49).

Type 3. Ambivalent attitude (the third factor accounting for $17 \%$ of the dispersion). This type is characterized with a low level of closeness (0.48), but with immersion in the relationship (0.55).

Type 4. Normative / healthy closeness (the fourth factor accounting for $15 \%$ of the dispersion). People of this type are characterized with a high closeness level (0.69) and a sufficient level of personal autonomy (0.72).

It was found that the said types of the attitudes women have towards their parents have statistically important differences in the following components of relationships: closeness $(\mathrm{H}=20.5$; $\mathrm{p}=0.00)$, freedom $(\mathrm{H}=11.4 ; \mathrm{p}=0.01)$, immersion in relationships $(\mathrm{H}=8, \mathrm{p}=0.00)$, general dissatisfaction with the situation $(\mathrm{H}=15 ; \mathrm{p}=0.00)$, mental and psychological tension $(\mathrm{H}=14.4 ; \mathrm{p}=0.00)$, anxiety $(\mathrm{H}=9.2$, $\mathrm{p}=0.02)$, responsibility guilt $(\mathrm{H}=12.2 ; \mathrm{p}=0.05)$, separation guilt $(\mathrm{H}=14.8 ; \mathrm{p}=0.00)$, survivor's guilt $(\mathrm{H}=7.2 ; \mathrm{p}=0.06)$. 
The attitude of a middle-aged woman to her parents is often accompanied by guilt towards them. To understand this variable better, we studied the structure of links shown by irrational forms of guilt and the components of attitudes to parents (Table 1).

This section may be divided by subheadings. It should provide a concise and precise description of the experimental results, their interpretation as well as the experimental conclusions that can be drawn.

Table 1. Correlations between attitudes of a middle-aged woman to her parents and irrational forms of her guilt $(\mathrm{n}=61)$

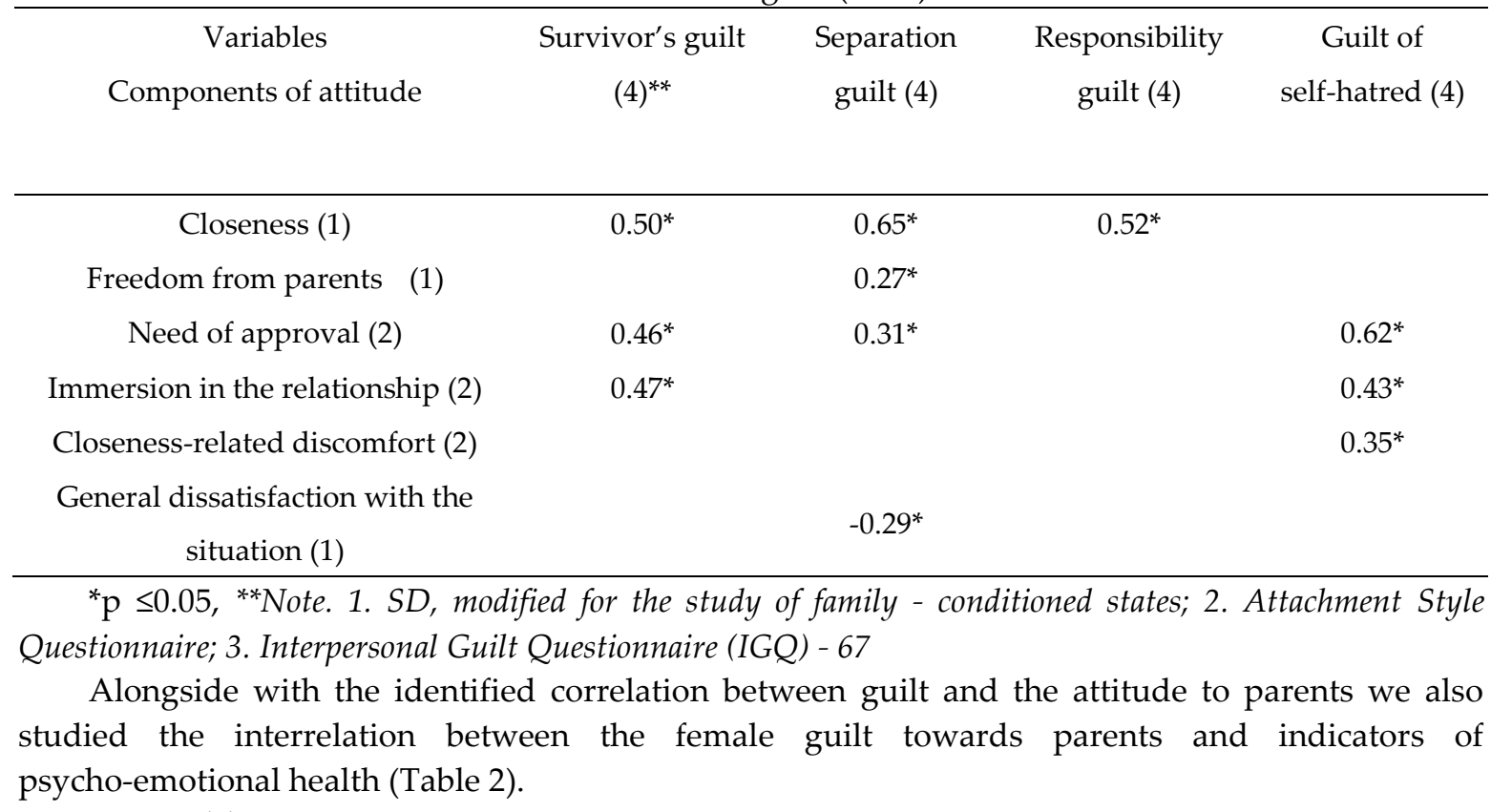

Table 2. Correlations between guilt toward parents in middle-aged women and their psycho-emotional health $(\mathrm{n}=61)$

\begin{tabular}{cc}
\hline Related variables & r-test \\
\hline Survivor's guilt (1) ${ }^{* * *}$ and autonomy(2) & $-0.34^{*}$ \\
Survivor's guilt (1) and environmental management (2) & $-0.29^{*}$ \\
Survivor's guilt (1) and self-acceptance (2) & $-0.46^{*}$ \\
Survivor's guilt (1) and autonomy (2) & $0.35^{*}$ \\
Survivor's guilt (1) and affection balance (2) & $0.38^{*}$ \\
Survivor's guilt (1) and man as an open system (2) & $0.36^{*}$ \\
\hline Separation guilt (1) and autonomy (2) & $-0.25^{*}$ \\
Separation guilt (1) and self-acceptance (2) & $-0.26^{*}$ \\
Separation guilt (1) and autonomy (2) & $0.35^{*}$ \\
Separation guilt (1) and affection balance (2) & $0.25^{*}$ \\
\hline Reparation guilt (1) and man as an open system (2) & $0.36^{*}$ \\
Responsibility guilt (1) and autonomy (2) & $-0.26^{*}$ \\
Responsibility guilt (1) and man as an open system (2) & $-0.30^{*}$ \\
\hline Guilt of self-hatred (1) and autonomy (2) & $0.32^{*}$
\end{tabular}


Guilt of self-hatred (1) and autonomy (2)

$0.37^{*}$

${ }^{*} \mathrm{p} \leq 0.05,{ }^{* *} \mathrm{p} \leq 0.01,{ }^{* * *} \mathrm{p} \leq 0.001,{ }^{* * *}$ Note 1. The Interpersonal Guilt Questionnaire-67; 2. Scales of psychological well-being

We identified specifics of attitude types manifested by adult women to parents, namely closeness and guilt, which made it necessary to identify correlations between the attachment types and the indicators of psycho-emotional health (Table 3).

Table 3. Correlations between attachment types and indicators of psychoemotional health in middle-aged women $(n=61)$

\begin{tabular}{cc}
\hline & Related variables \\
\hline Certainty in relationships (1) ${ }^{* *}$ and positive relationships(2) & $0.39^{*}$ \\
Certainty in relationships (1) and environmental management (2) & $0.28^{*}$ \\
Certainty in relationships (1) and autonomy (2) & $0.34^{*}$ \\
Certainty in relationships (1) and self-acceptance (2) & $0.30^{*}$ \\
Certainty in relationships (1) and aims in life (2) & $0.26^{*}$ \\
Certainty in relationships (1) and affection balance (2) & $0.31^{*}$ \\
Certainty in relationships (1) and man as an open system (2) & $0.35^{*}$ \\
Certainty in relationships (1) and meaningfulness of life (2) & $0.38^{*}$ \\
\hline Closeness-related discomfort (1) and positive relationships (2) & $-0.29^{*}$ \\
Closeness-related discomfort (1) and affection balance (2) & $0.34^{*}$ \\
Closeness-related discomfort (1) and autonomy (2) & $0.26^{*}$ \\
\hline Need of approval(1) and autonomy (2) & $-0.43^{*}$ \\
Need of approval (1) and self-acceptance (2) & $-0.35^{*}$ \\
Need of approval (1) and affection balance (2) & $0.50^{*}$ \\
Immersion of approval (1) and autonomy (2) & $0.47^{*}$ \\
\hline Immersion in relationship (1) and autonomy (2) & $-0.32^{*}$ \\
\hline Imm relationship (1) and autonomy (2) & $-0.38^{*}$
\end{tabular}

${ }^{*} \mathrm{p} \leq 0.05,{ }^{* *}$ Note: 1 . Attachment Style Questionnaire; 2. Scales of psychological well-being

To validate the main research hypothesis we used the one-factor dispersion analysis to study the correlation between the attitude types to parents and the indicators of psychoemotional health in middle-aged women. It was found that the type of attitude to parents influences such indicators of female psychoemotional health as self-acceptance $(\mathrm{F}=3.4 ; \mathrm{p}=0.02)$, balance of affection (general satisfaction with life $(\mathrm{F}=5.8, \mathrm{p}=0.00)$, man as an open system (open to new experience, $\mathrm{F}=3.2, \mathrm{p}=0.03$ ), autonomy $(\mathrm{F}=6.6, \mathrm{p}=0.00)$.

Table 4 shows the average values of the indicators of psychoemotional health in groups of women with different attitude types.

Table 4. Average values of the psychoemotional health indicators in groups of women with different attitude types

\begin{tabular}{ccccc}
\hline $\begin{array}{c}\text { Types of attitude / } \\
\text { Indicators of } \\
\text { psychoemotional health }\end{array}$ & Self-acceptance & $\begin{array}{c}\text { Affection } \\
\text { balance } \\
\text { (reverse scale) }\end{array}$ & $\begin{array}{c}\text { Man as an open } \\
\text { system (open to new } \\
\text { experience) }\end{array}$ & $\begin{array}{c}\text { Autonomy } \\
\text { (Reverse }\end{array}$ \\
\hline Healthy closeness & 57.9 & 85.3 & 62 & 39.8 \\
Strong attachment & 52.1 & 97.6 & 65.3 & 44.5 \\
Ambivalent attitude & 53.2 & 104.3 & 60.2 & 46.3 \\
Distancing & 61.3 & 84.6 & 58.1 & 36.9 \\
\hline
\end{tabular}


Therefore, the type of attitude to parents characterized by guilt and a certain attachment style influences the psycho-emotional health indicators in middle-aged women and is related to their psychological well-being. The role overload related to the necessity to combine family and professional duties with care for elderly parents makes women with deep attachment to parents most vulnerable. It is accompanied with guilt, decreases female self-acceptance, blurs the personal boundaries and depletes personality resources of middle-aged women.

\subsection{Study 2}

The objective of this research stage was to study how the style of separation from mothers influences the indicators of psychoemotional health in middle-aged women.

1. Below there are results of comparing the values obtained for the sample, divided according to the variable of conflicting style as a more general criterion. To verify the hypothesis and solve tasks we used the median filter $(\mathrm{Me}=\mathrm{Mo}=4)$; as a result 20 people were excluded from this stage of the research. We had groups with higher values of separation on the scale separation style $(n=39 ; M=4.4)$, which demonstrates a successful separation style. Groups with lower values $(n=26, M=3.2)$ demonstrate a conflictive separation style. Then we identified a number of significant differences in the indicators of psychoemotional health in middle-aged women with successful and conflictive separation styles (Table 5).

Table 5. Differences in the indicators of psychoemotional health in middle-aged women with a successful (n1=39) and a conflictive (n2=26) style of separation from mothers

\begin{tabular}{|c|c|c|c|}
\hline $\begin{array}{c}\text { Indicators of separation from } \\
\text { mothers and of psychoemotional } \\
\text { female health } \\
\text { Variables }\end{array}$ & $\begin{array}{c}\text { Mann-Whitney } \\
\text { Test, } \\
\text { U }\end{array}$ & $\begin{array}{l}\text { Avenge rank of } \\
\text { the group with } \\
\text { successful } \\
\text { separation } \\
\text { n1 }=39\end{array}$ & $\begin{array}{l}\text { Avenge rank of the } \\
\text { group with } \\
\text { conflictive } \\
\text { separation } \\
\text { n2 }=26\end{array}$ \\
\hline Separation style $(1)^{* * * *}$ & $0.000^{* * *}$ & 46 & 13.5 \\
\hline Functional separation (1) & $323,5^{* *}$ & 37.71 & 25.94 \\
\hline Aims in life (2) & $361.5^{*}$ & 36.73 & 27.4 \\
\hline $\begin{array}{l}\text { Life process (emotional saturation } \\
\text { and interest in life) (2) }\end{array}$ & $361.5^{*}$ & 36.73 & 27.4 \\
\hline Life as locus of control (2) & $335.0^{*}$ & 37.41 & 26.38 \\
\hline $\begin{array}{l}\text { General indicator of life } \\
\text { meaningfulness (2) }\end{array}$ & $336.5^{*}$ & 37.37 & 26.44 \\
\hline $\begin{array}{l}\text { Anxiety in the description of the } \\
\text { future (3) }\end{array}$ & $295.5^{* *}$ & 27.58 & 41.13 \\
\hline Particular image of the future (3) & $340.0^{*}$ & 28.72 & 39.42 \\
\hline $\begin{array}{l}\text { Indicators of neurotic symptoms in } \\
\text { life-path drawing (4) }\end{array}$ & $306.5^{* *}$ & 27.86 & 40.71 \\
\hline $\begin{array}{l}\text { Indicators of resources, possibilities } \\
\text { and means (4) }\end{array}$ & $349.0^{*}$ & 37.05 & 26.92 \\
\hline
\end{tabular}

\section{The grouping variable: separation style}

${ }^{* *} \mathrm{p} \leq 0.05,{ }^{* *} \mathrm{p} \leq 0.01,{ }^{* * *} \mathrm{p} \leq 0.001,{ }^{* * * *}$ Note :1. Psychological Separation Inventory; 2. Purpose-in-Life

Test; 3 . The projective method of incomplete sentences; 4 . The method of metaphors analysis.

The conflicting separation style is dominated by the indicators of future-related anxiety $(\mathrm{U}=295.5$, $\mathrm{p}=0.003)$, manifestations of neurotic symptoms in life-path drawings $(\mathrm{U}=306.5, \mathrm{p}=0.002)$, particular image of the future $(\mathrm{U}==340 ; \mathrm{p}=0.02)$.

To verify the research hypothesis, i.e. how the style of separation from mothers influences the indicators of psycho-emotional health in adult daughters; we used the one-factor regression 
analysis. The results are shown in Table 6, with the separation style of a middle-aged woman from her mother served as the independent variable.

Table 6. Data on the influence of the separation style on the indicators of psychoemotional health in middle-aged women

\begin{tabular}{cccc}
\hline Dependent variables & $\begin{array}{c}\text { Value of } \\
\text { criterion } \boldsymbol{\beta}\end{array}$ & $\mathbf{p}$ & $\begin{array}{c}\text { Dispersion } \\
\text { percentage R2 }\end{array}$ \\
\hline Functional separation (1) & 0.38 & 0.00 & 0.146 \\
Aims in life (2) & 0.27 & 0.03 & 0.076 \\
Life process (2) & 0.32 & 0.00 & 0.105 \\
Me as locus of control (2) & 0.36 & 0.00 & 0.129 \\
Life as locus of control (2) & 0.24 & 0.05 & 0.059 \\
Meaningfulness of life (general value) (2) & 0.37 & 0,00 & 0.135 \\
Anxiety in the description of the future (3) & -0.33 & 0.00 & 0.109 \\
Indicators of neurotic symptoms in life-path & -0.35 & 0.00 & 0.122 \\
drawing (4) & & & \\
Protective aggression (4) & -0.24 & 0.05 & 0.057 \\
\hline
\end{tabular}

Independent variable Separation style

*Note : 1. Psychological Separation Inventory; 2. Purpose-in-Life Test; 3. The projective method of incomplete sentences; 4 . The method of metaphors 'analysis

It was found that the style of separation from mothers influences such indicators of psychoemotional health in middle-aged women as aims in life, life process, Me as locus of control, life as control locus, meaningfulness of life, anxiety in the descriptions of the future, neurotic symptoms and protective aggression. It is worth mentioning that the content analysis of the data obtained with the method of metaphor analysis enabled us to use the statistical analysis. Due to this, it became possible to trace the degree of the influence of the separation style on manifestations of neurotic symptoms and signs of protective aggressive reactions.

Therefore, we may conclude that an incomplete unsuccessful separation of adult women from mothers, especially in the situation of the vertical change, may be a risk factor and makes their psychoemotional health worse. This style results in an interpersonal conflict that hinders new life prospects and becomes a source of difficult emotional states: high tension, anxiety, and dissatisfaction, inability to control own life.

\section{Discussion}

Using qualitative and quantitative methods and the typology of attachment, we identified four types of attitude a middle-aged woman can have towards her parents. Strong attachment is characterized by a symbiotic attachment to parent, euphoric feelings towards them and a deep feeling of quilt. Healthy closeness is characterized by the optimal distancing from parents and a medium level of satisfaction with this relationship. Ambivalent attitude is characterized by strong devotion to parents and a high level of immersion in conflicts with them as well as with a wide range of negative emotions towards them. Distancing is characterized by detachment, the formal relationship with them, anxiety, and general dissatisfaction with the situation, psychological and mental tension, and low level of closeness. Psychological well-being and psychoemotional health of a woman are strongly influenced by the type of her attitude to parents [33, 34, 35]. These relationships can become a significant personal resource, enhancing the woman's family identity and generational integrity; developing her understanding of life value and the inevitability of its end; promoting the feeling of control in her own life. However, when major relationships with aging parents come to a crisis and new relationships are formed, women can develop a strengthening internal personal conflict. It ruins processes of self-identification and leads to the misbalance of roles. This lack of psychological well-being is aggravated by the life situation related 
to the role overload in middle-aged women, which leads to the deterioration of their psychoemotional health.

The analysis of differences in the indicators of psychoemotional health manifested by middle-aged women towards their parents showed that women to whom mothers are emotionally closer are more inclined to have negative emotions in their relationships with elderly parents than those to whom fathers are closer. Their indicators look as follows: general dissatisfaction with the relationship $(\mathrm{p}=0.02)$, mental and psychological tension $(\mathrm{p}=0.03)$, anxiety $(\mathrm{p}=0.03)$. In this case, responsibility guilt is typical $(\mathrm{p}=0.04)$. Women who are more caring for their parents are more sure in their relationship with them $(p=0.04)$ than women of the ambivalent type. Women with a low level of closeness, but a high degree of immersion in the relationship with parents (the ambivalent type) need more parental approval than the women of the first group, and, therefore, are more dependent on parents psychologically ( $\mathrm{p}=0.04$ ). These respondents are more likely to experience the survivor's guilt $(\mathrm{p}<0.05)$ than those in whose life parental care and care for parents are balanced. Therefore, the authors proved the hypothesis that the type of attitude an adult woman has towards her parents is a factor of her psychological well-being and her psychoemotional health.

Women's attitude to their elderly parents is often accompanied by the feeling of guilt, i.e. irrational forms of guilt, especially of those women who are close to parents and need their approval.

It should be mentioned that mid-age adulthood is characterized by a set of direct correlations between the feeling of guilt and such a component of psychological well-being as man as an open system. It may be so because guilt in adulthood (especially responsibility guilt that tends to increase at this stage of life) is a psychological mechanism that motivates a woman to adhere to the eudemonic lifestyle, i.e. to actualize herself via care for the Other - in this case, for ageing parents and growing children [33,36]. On the other hand, the role of guilt in the female personal development is not so straightforward. In its normative values, it can promote constructive personal development. High values of guilt can indicate the deterioration of personal autonomy, blurred personal borders, the deterioration of self-acceptance, difficulties in everyday life management, lack of control over the situation. Therefore, a woman's feeling of guilt related to her parents is a subjective factor of her psychoemotional health.

One more feature of the attitude to parents is the type of attachment. The analysis of the type-related characteristics and their interrelation with the indicators of psychoemotional health showed that immersion into the relationship and the need of approval are associated with the low level of autonomy in women and the low level of self-acceptance. Such women are oriented at the external evaluation, have an internal conflict and manifest a child-like position in the relationship with the mother.

The major result of our research is as follows: women of the types Distancing and Healthy closeness are better-off psychologically and manifest higher indicators of psychoemotional health. The most vulnerable women in the situation of the triple load are of attachment types Ambivalent attitude and Strong attachment.

The study of differences in the indicators of psychoemotional health in women with a different style of separation from mothers showed the following important results. Women with a complete successful separation have a certain sense of life (Meaning in life $p=0.05$, Aims in life $p=0.02$ ), believe in their abilities (Life as locus of control $\mathrm{p}=0.02$ ), are able to function successfully and independently in the present and in the future (Functional separation $p=0.01$, Life process $p=0.05$ ). Such women prefer active strategies aimed to solve problems and overcome difficulties, take the responsibility, actualize internal and external resources (Indicators of resources, possibilities and means, $\mathrm{p}=0.02$ ).

Middle-aged women who are experiencing an incomplete and conflictive separation from mothers manifest protective aggressive reactions and expressly display the lack of emotional well-being (Neurotic symptoms in describing the life timeline $\mathrm{p}=0.00$ ). It was found with the method of drawing metaphors content. The high level of anxiety, protective and aggressive intention, fears can be regarded as a way to reduce a conflict and to get rid of responsibility for their own life in the future. The research demonstrated that all this could result from an improper process of separation from mothers. 
At this stage of life, a woman's dependence on her mother becomes a barrier for her own existential needs. It hinders planning and makes it more difficult for a woman to adapt to the situation in which she has to combine several roles - employee/professional, mother, wife, and caregiver/guardian. Describing their future, women see particular tasks (have a child, go to the seaside), but this future is associated with anxiety: "when I think of the future, I am afraid», «I hope that the future will be peaceful, without problems», «I am anxious when I think about my future», «I am concerned about my future» (The particular image of the future, $\mathrm{p}=0.02$, Anxiety in the description of the future $\mathrm{p}=0.00$ ). We consider it as a compensation for the undesired past and present and the immersion in the desirable future that will be free from the anxiety of separation (Purpose-in-Life Test; The projective method of incomplete sentences).

The results of the regressive analysis proved that the style of separation from mothers in the adulthood is manifested by women via such psychoemotional indicators as the meaningfulness of the present and the future, the ability of self-determination and control over their own lives. The plans for the future are not illusions, but supported with taking responsibility for these plans. Emotionally, these women are more mature, they are ready to show empathy and achieve the internal and external balance with themselves and the world around them.

The decrease in the separation indicators are accompanied with lack of freedom from guilt, anxiety, lack of trust, responsibility, indignation and anger towards mothers. The anxiety related to the perception of the own life path increases. The lack of separation from the maternal image causes protective behaviour that is manifested through auto- and hetero-aggression (Neurotic symptoms, $p=0.00$, Protective aggression, $p=0.05$, the method of metaphor analysis) $[33,34,36]$.

The increase in the anxiety indicators while reflecting on the own life path and oneself as the subject of the own life under the conflictive separation is regarded as caused by the lack of independence and uncertainty of a woman in her own maturity.

Both empirical studies showed that psycho-emotional health of the middle-aged woman deteriorates because of both an objectively difficult life situation related to their work overload and style of life and subjective factors, such as the woman's attitude to her parents, the type of attachment, the style of separation from mothers (including guilt).

\section{Conclusions}

The research proved the following. Psycho-emotional health of middle-aged Russian women depends on contextual / situational factors (their way of life and style of life) and subjective factors including the attitude of women to their parents, the type of attachment and the style of separation.

The life situation of middle-aged women has clear objective peculiarities. They include the role overload that is determined by the necessity to combine the major social roles: employee/ professional, mother, wife, and caregiver. This period is characterized by a crisis in the relationship with growing children and ageing parents. The way of resolving this existential crisis influencing the manner of solving problems in the future and he state of the woman's psychological well-being and psychoemotional health. The major indicators of lack of well-being and health in middle-aged women are high levels of anxiety, tension, dissatisfaction, negative and overcritical attitude to self, uncertainty in own abilities, difficulties in or impossibility of life planning, anxiety about the future. The success of the adaptation to new life circumstances (adopting the new role of the guardian and caregiver to own parents), well-being and psychoemotional health depend on a number of subjective personal factors. These factors include the attitude to parents, the type of attachment, the style of separation from mother (all the three components involve guilt toward their family members).

The high level of cognitive and emotional autonomy as well as active participation in the life of children and parents, care for them and certainty in these relations add to the middle-aged woman's psychological well-being and psychoemotional health.

Author Contributions: Conceptualization, Maria V. Saporovskaia and Tatiana L. Kryukova; methodology, Tatiana L. Kryukova, Maria V. Saporovskaia; software, Maria E. Voronina, Elena V. Tikhomirova; validation, Maria E. Voronina, Elena V. Tikhomirova; formal analysis, Elena V. Tikhomirova, Maria E. Voronina; 
investigation, Maria E. Voronina, Elena V. Tikhomirova; resources, Svetlana A. Khazova; data curation, Elena V. Tikhomirova; writing-original draft preparation, Maria V. Saporovskaia, Tatiana L. Kryukova, Elena V. Tikhomirova; writing-review and editing, Tatiana L. Kyrukova; visualization, Elena V. Tikhomirova; supervision, Svetlana A. Khazova; project administration, Anna G. Samokhvalova; funding acquisition, Tatiana L. Kryukova. All authors have read and agreed to the published version of the manuscript.

Funding: This research is funded by Ministry of Higher Education and Science project N FZEW-2020-0005

Acknowledgments: We thank the study participants for taking part in our research

Conflicts of Interest: The authors declare no conflict of interest.

\section{References}

1. https://news.un.org/en/ (accessed on 20.10.2020)

2. https://olgasofronova.ru/o-polozhenii-zhenshhin-v-obshhestve-nacionalnaya-strategiya-dejstvij-v-interes ax-zhenshhin-na-2017-2022-gody.html(accessed on 19.10.2020)

3. https://rosstat.gov.ru/bgd/regl/b19_34/Main.htm (accessed on 19.10.2020)

4. Thomas, A.J.; Mitchell, E.S.; Woods, N.F. Undesirable stressful life events, impact, and correlates during midlife: observations from the Seattle midlife women's health study. Womens `midlife health 2019, 5(1). Available online: https:/www.ncbi.nlm.nih.gov/pmc/articles/PMC6318955/ (accessed on 12.09.2020).

5. Woods-Giscombé, C.L.; Lobel, M.; Zimmer, C.; et al. Whose stress is making me sick? Network-stress and emotional distress in African American women. Issues Mental Health Nursing 2015, 36(9), 710-717.

6. Kulik, L.; Shilo-Levin, S.; Liberman, G. Multiple Roles, Role Satisfaction, and Sense of Meaning in Life: An Extended Examination of Role Enrichment Theory. Journal of Career Assessment 2015, 23(1), 137-151.

7. Larsen, N.J. Support given by women to their mothers and mothers-in-law and relationship quality over time. Retrospective Theses and Dissertations 11476. Iowa State University Capstones, USA, 1997. https://lib.dr.iastate.edu/rtd/11476

8. Baruch, G. K.; Barnett, R. Role quality, multiple role involvement, and psychological well-being in midlife women. Journal of Personality and Social Psychology 1987, 51(3), 578-585.

9. https://www.who.int/. Available online: URL:https://www.who.int/ru/news-room/facts-in-pictures/detail/mental-health (accessed on 10.10.2020).

10. Solomon, D.N.; Hansen, L.; Baggs, J.G. It's All about the Relationship: Cognitively Intact Mother-Daughter Care Dyads in Hospice at Home. The Gerontologist 2018, 58(4), August, 625-634.

11. Abrahamson, L.Y.; Seligman, M.T.; Teasdale, J.D. Learned helplessness in humans: critique and reformulation. Abnormal psychology 1978, 87(1), 589-599.

12. Pow, J.; Lee-Baggley, D.; DeLongis, A. Who is most likely to seek and give support in the face of agentic and communal threat? The roles of extraversion and agreeableness. Journal of Research in Personality 2017, 70, 66-72.

13. Manczak, E. M.; DeLongis, A.; Chen, E. Does empathy have a cost? Diverging psychological and physiological effects within families. Health Psychology 2016, 35(3), 211-218.

14. Gullickson, T. Review of The Sandwich Generation: Caught Between Growing Children and Aging Parents. Contemporary Psychology: A Journal of Reviews 1993, 38(4), 433-433.

15. Kyle, L.; Bower, K.L.; Kemp, C.L.; Burgess, E.O.; Atkinson, J.L._Complexity of care: Stressors and strengths among low-income mother-daughter dyads. Journal of Women $\mathcal{E}$ Aging 2020, 32(2), 131-148.

16. Pope, N.D.; Kolomer, S.; Glass, A.P. How Women in Late Midlife Become Caregivers for Their Aging Parents. Journal of Women E Aging 2012, 24(3), 242-261.

17. Hodge, D.R.; Sun, F. Positive feelings of caregiving among Latino Alzheimer's family caregivers: Understanding the role of spirituality. Aging $\mathcal{E}$ Mental Health 2012, 16(6), 689-698. 
18. Park, J.; Tolea, M.I.; Arcay, V.; Lopez, Y.; Galvin, J.E. Self-efficacy and social support for psychological well-being of family caregivers of care recipients with dementia with Lewy bodies, Parkinson's disease dementia, or Alzheimer's disease. Social Work in Mental Health 2019, 17(3), 253-278.

19. Pinquart, M.; Sörensen, S. Differences Between Caregivers and Non-caregivers in Psychological Health and Physical Health: A Meta-Analysis. Psychology and Aging 2003, 18(2), 250-267.

20. King, D. B.; DeLongis, A. When couples disconnect: Rumination and withdrawal as maladaptive responses to everyday stress. Journal of Family Psychology 2014, 28(4), 460-469.

21. Habermann, B.; Hines, D.; Davis, L. Caring for Parents with Neurodegenerative Disease: A Qualitative Description. Clinical Nurse Specialist 2013, July/August, 27(4), 182-187.

22. Ryff, C. D.; Keyes, C. L. M. The structure of psychological well-being revisited. Journal of Personality and Social Psychology 1995, 69(4), 719-727.

23. Osgood, C. E. Semantic differential technique in the comparative study of cultures. American Anthropologist 1964, 66(3), 171-200, part 2.

24. Handbook of Family Measurement Techniques / Eds. by J. Touliatos, B.F. Perlmutter, M.A. Straus. 3 Volume Set. Sage Publications, Inc. 2001 - 2003. V. 3, pp. 11 - 12.

25. O'Connor, L.E.; Berry, J.W.; Weiss, J.; Bush, M.; Sampson, H. Interpersonal Guilt Questionnaire - IGQ. Journal of clinical psychology 1997, 53(1), 73-89.

26. Hoffman, J.A. (1984). Psychological separation of late adolescents from their parents. Journal of Counseling Psychology 1984, 31, 170-178.

27. Dzukaeva, V. Adaptation of Psychological Separation Inventory (PSI) for Russian sample. Procedia - Social and Behavioral Sciences 2014, 146, $216-221$.

28. Crumbaugh, J. C., \& Maholick, L. T. Manual of instructions for the Purpose in Life test. Abilene, TX: Viktor Frankl Institute of Logotherapy, 1967.

29. Leontiev, D.A. Personal meaning: A challenge for psychology. The Journal of Positive Psychology 2013, 8, 459-470.

30. Holaday, M.; Smith, D. A.; Sherry, A. Sentence Completion Tests: A review of the literature and results of a survey of members of the Society of Personality Assessment. Journal of Personality Assessment 2000, 74(3), 371-383.

31. McAdams, D. P.; Zeldow, P. B. Construct validity and content analysis. Journal of Personality Assessment 1993, 61, 243-245.

32. Solomin, I. The method of analysis of metaphors of life line; SPb.: IMATON, Russia, 2007; 8-16.

33. Kryukova, T. L.; Saporovskaia, M. V.; Voronina, M. E. Predictors of middle aged women`s psychological well-being: attitudes toward parents. Social Welfare: Interdisciplinary Approach 2018, 8(2), 20-29.

34. Charles, M.; Frank, S.; Jacobson, S.; Grossman, G. Repetition of the remembered past: patterns of separation - individuation in two generations of mothers and daughters. Psychoanalytic Psychology 2001, 18(4), 705-728.

35. Thomas, P. A.; Liu, H.; Umberson, D. Family Relationships and Well-Being. Innovation in aging 2017, 1(3), $1-11$.

36. Flouri, E. Women`s psychological distress in midadulthood: The role of childhood parenting experiences. European Psychologist 2005, 10(2), 116-123. 